\title{
Risk factors of uterine contraction after ureteroscopy in pregnant women with renal colic
}

\author{
Chunjing $\mathrm{Li}^{1} \oplus$ - Liwen Guo ${ }^{2} \cdot \mathrm{Mi}_{\mathrm{Luo}}{ }^{1} \cdot$ Mingjuan Guo ${ }^{1}$ Jierong $\mathrm{Li}^{1} \cdot$ Shilin Zhang ${ }^{1} \cdot$ Guoqing Liu ${ }^{1}$
}

Received: 20 February 2021 / Accepted: 2 June 2021 / Published online: 5 July 2021

(c) The Author(s) 2021

\begin{abstract}
Background Ureteroscopy is widely applied in pregnant women with renal colic, but such patients are easy to experience uterine contraction after surgery. There are many factors which may affect uterine contraction, this study aims to explore the risk factors of uterine contraction triggered by ureteroscopy in pregnant women with renal colic.

Methods One hundred and one pregnant women were retrospectively analyzed, the patients were hospitalized because of severe renal colic. All patients received ureteroscopy during which double $\mathrm{J}$ catheters were inserted into ureters for drainage. Patients received other medical treatments individually according to their condition and uterine contractions were detected by EHG within $12 \mathrm{~h}$ after operation. Patients were classified as group A (uterine contraction) and group B (no uterine contraction) according to the presence or absence of continuously regular uterine contraction. Clinical characteristics were collected for further analysis, including history of childbirth, anesthesia method, application of phloroglucinol or not, operation time, Oxygen inhalation or not, pain relief or not after surgery, systemic inflammatory response syndrome (SIRS) occurred or not. A binary logistic regression analysis model was established to explore whether such clinical characteristics were relevant to uterine contraction after ureteroscopy.

Results Continuously regular uterine contraction presented in 46 pregnant women within $12 \mathrm{~h}$ after ureteroscopy, making the incidence of uterine contraction as high as $45.54 \%$. The presence of uterine contraction was related to the following factors $(P<0.05)$ : history of childbirth (primipara versus multipara)(OR 6.593, 95\% CI 2.231-19.490), operation time (each quarter additional) (OR 2.385, 95\% CI 1.342-4.238), application of phloroglucinol (yes versus not) (OR 6.959, 95\% CI 1.416-34.194), pain relief after surgery(yes versus not)(OR 6.707, 95\% CI 1.978-22.738), SIRS occurred after surgery (yes versus not) (OR 0.099, 95\% CI 0.014-0.713).

Conclusion Continuously regular uterine contraction is easy to occur within $12 \mathrm{~h}$ after ureteroscopy in pregnant women. SIRS occurred after surgery is a risk factor for uterine contraction; on the contrary, no history of childbirth, shorter operation time, application of phloroglucinol, pain relief after surgery are protective factors.
\end{abstract}

Keywords Pregnant women $\cdot$ Renal colic $\cdot$ Ureteroscopy $\cdot$ Uterine contraction $\cdot$ Risk factors

\section{Background}

Chunjing Li and Liwen Guo have contributed equally to this work.

\section{Chunjing Li}

164194249@qq.com

$\triangle$ Guoqing Liu

guoqingliu1961@sina.com

1 Department of Urology, Affiliated Foshan Maternal and Child Healthcare Hospital, Southern Medical University, Foshan, Guangdong 528000, People's Republic of China

2 Department of Gynecology, Ningde Municipal Hospital, Fujian Medical University, Ningde, Fujian 352100, People's Republic of China
Renal colic is one of the most common non obstetric pain and pregnancy emergencies in pregnant women [1]. The incidence range from 1:200 to 1:2000. For pregnant women, renal colic could lead to severe pregnancy complications, such as abortion or premature delivery [2]. The main cause of renal colic in pregnant women contains urinary calculi, ureteral stricture, and ureteral obstruction caused by external compression and so on. Spasmolysis, pain relief, double$\mathrm{J}$ tube drainage or percutaneous nephrostomy are options considered to be effective for renal colic [3]. Due to the limitation of drug application for pregnant women and the 
trauma caused by nephrostomy $[4,5]$, thereby ureteroscopy is widely considered to be a preferable choice. Uncontrollable pain and gradually aggravating ureteral obstruction are surgical indications for ureteroscopy [6, 7]. Complications such as urinary tract infection and so on are common after ureteroscopy, but premature delivery or abortion derived from regular uterine contraction is one of the most severe complications $[8,9]$. Persistent and intense uterine contraction, which could lead to cervical dilatation, is a sign of threatened preterm birth [10], even if the length of cervical canal changes little [11], the premature birth rate of pregnant women with renal colic could be as high as $12.8 \%$ according to previous literatures [12]. Therefore, preventing the occurrence of continuously regular uterine contraction is the premise to avoid adverse pregnancy events. The occurrence of uterine contraction is interactive result of multiple factors [13]. However, there is little literature about risk factors of uterine contraction caused by ureteroscopy. In this study, we retrospectively analyzed 101 pregnant women who were received ureteroscopy to explore the risk factors of uterine contraction after such surgery.

\section{Methods}

One hundred and one pregnant women who received ureteroscopy in our hospital from January 2010 to Mar 2020 were retrospectively analyzed, including 46 primiparas and 55 multipara. The patients, at 20-36 weeks of gestation, were admitted because of severe renal colic. The mean duration of hospital stay was $5.92 \pm 1.83$ day. The diseases included ureteral calculi (62 cases), renal calculus (10 cases), ureteral stricture (18 cases) and ureteral obstruction (11 cases) caused by fetal oppression. The cervical was not opened and there was no continuously regular uterine contraction detected by EHG before ureteroscopy. A visual analog scale/ score (VAS) was conduct to evaluate the pain degree, if the score was more than 7 , then phloroglucinol $80 \mathrm{mg} /$ single-use or pethidine $75-100 \mathrm{mg} /$ single-use was prescribed for every patient. If the renal colic still had little relief or occurred again in less than $8 \mathrm{~h}$, then patients would receive ureteroscopy (rigid ureteroscope, Wolf, 9.8Fr, Richard-wolf, Germany) and double-J catheters(6Fr, Boston scientific, MA,
US) drainage on the basis of informed consent. In fact, for all the 101 patients before surgery and 26 patients among them after surgery, the VAS scores were all more than 7 . The anesthesia methods included general anesthesia (13 cases), lumbar anesthesia (39 cases) and spinal-epidural anesthesia (49 cases). After operation, EHG was used again to monitor continuously regular uterine contraction for $12 \mathrm{~h}$. Phloroglucinol was applied in 42 patients; Oxygen inhalation was given to 61 patients; Renal colic was not completely relieved in 26 patients immediately after surgery but disappeared after several hours; Systemic inflammatory response syndrome (SIRS) occurred in 11 patients but nobody progressed to Sepsis. According to the occurrence of continuously regular uterine contraction after operation, the patients were divided into group A and group B. Group A $(n=46)$ presented regular contractions within $12 \mathrm{~h}$ after surgery and received magnesium sulfate or ritodrine hydrochloride, while group B $(n=55)$ did not present regular contractions within $12 \mathrm{~h}$ after ureteroscopy. Patients' differences in age, weight and gestational week between the two groups were not statistically significant $(P>0.05)$ (Tab 1$)$.

Diagnosis and treatment criteria were as follows: the uterine contraction were monitored continuously after admission until $12 \mathrm{~h}$ after operation. Any uterine contraction lasted for more than $30 \mathrm{~s}$ with a interval less than $15 \mathrm{~min}$ would be considered as real uterine contraction [14]. If the length of cervical canal shortened, $25 \%$ magnesium sulfate or $0.01 \%$ ritodrine hydrochloride was prescribed immediately to inhibit uterine contraction. In view of the side effects of uterine contraction inhibitors, the following indicators were needed to monitor closely during the application of such drugs. (1) Breath frequency no less than 16 times/min; (2) heart rate no more than 120 times/min; (3) knee reflex existed; (4) urine volume not less than $17 \mathrm{ml} / \mathrm{h}$ [15]. The diagnostic criteria of systemic inflammatory response syndrome were as follows: (1) body temperature $>38.0{ }^{\circ} \mathrm{C}$ or body temperature $<36.0{ }^{\circ} \mathrm{C}$; (2) heart rate $>90$ beats/min; (3) respiration rate $>20$ beats/min or excessive breathing with $\mathrm{PaCO}_{2}<32 \mathrm{mmHg}$; (4) blood $\mathrm{WBC}>12.0 \times 10^{9} / \mathrm{L}$, or $\mathrm{WBC}<4.0 \times 10^{9} / \mathrm{L}$ or immature $\mathrm{WBC}>10.0 \%$ [16].

Statistics: in addition to age, weight and gestational weeks, the other clinical characteristics of patients in the two groups were collected, including history of childbirth,

0 Clinical characteristics of patients in two groups

\begin{tabular}{|c|c|c|c|c|c|c|c|c|}
\hline \multirow[t]{2}{*}{ Group } & \multirow[t]{2}{*}{$\operatorname{Age}(\mathrm{Y})$} & \multirow[t]{2}{*}{ Weight $(\mathrm{Kg})$} & \multirow[t]{2}{*}{ Gestational week (W) } & \multirow[t]{2}{*}{ Operation time (min) } & \multicolumn{4}{|c|}{ Disease species (case) } \\
\hline & & & & & Ureterolith & $\mathrm{RS}$ & US & $\overline{\mathrm{UO}}$ \\
\hline $\mathrm{A}(n=46)$ & $28.0 \pm 5.7$ & $58.0 \pm 8.3$ & $26.4 \pm 4.4$ & $28.8 \pm 16.3^{*}$ & 23 & 5 & 13 & 5 \\
\hline $\mathrm{B}(n=55)$ & $29.8 \pm 5.2$ & $61.6 \pm 9.6$ & $25.8 \pm 4.7$ & $23.8 \pm 11.1$ & 39 & 5 & 5 & 6 \\
\hline
\end{tabular}

$R S$ renal stone, $U S$ ureteral stricture, $U O$ ureteral obstruction

${ }^{*} P<0.05$ 
anesthesia method, operation time (each quarter additional), phloroglucinol application or not, oxygen inhalation or not, renal colic relief or not, and SIRS occurrence or not. The above clinical features were analyzed to explore whether they were related to the presence of uterine contraction (Table 2).

All statistical analyses were performed by SPSS version 23.0 (IBM, New York, NY). Measurement data were showed as mean \pm standard deviation $(\mathrm{x} \pm \mathrm{s})$, rate or percentage were compared by Chi-squared test. A binary logistic regression model was established to explore the clinical characteristics which might be related to uterine contraction, adjusted odds ratio (OR) and $95 \%$ confidence interval (CI) were analyzed. The $P$ value less than 0.05 was considered to be statistically significant.

\section{Result}

In all 101 patients, continuously regular uterine contractions which could be inhibited by magnesium sulfate or ritodrine occurred in 46 patients within $12 \mathrm{~h}$ after operation.

Table 2 Clinical characteristics for logistics analysis

\begin{tabular}{|c|c|c|}
\hline Clinical characteristics & Group A (case) & $\begin{array}{l}\text { Group B } \\
\text { (case) }\end{array}$ \\
\hline \multicolumn{3}{|l|}{ History of childbirth } \\
\hline Primipara & 30 & 16 \\
\hline Multipara & 16 & 39 \\
\hline \multicolumn{3}{|l|}{ Anesthesia methods } \\
\hline General anesthesia & 7 & 6 \\
\hline Lumbar anesthesia & 19 & 20 \\
\hline Spinal-epidural anesthesia & 20 & 29 \\
\hline \multicolumn{3}{|l|}{ Operation time (min) } \\
\hline$\leq 15$ & 9 & 17 \\
\hline$>15 \leq 30$ & 22 & 25 \\
\hline$>30 \leq 45$ & 6 & 11 \\
\hline$>45 \leq 60$ & 6 & 2 \\
\hline$>60 \leq 75$ & 3 & 0 \\
\hline \multicolumn{3}{|l|}{ Application of phloroglucinol } \\
\hline Yes & 36 & 49 \\
\hline No & 10 & 6 \\
\hline \multicolumn{3}{|l|}{ Oxygen inhalation } \\
\hline Yes & 31 & 28 \\
\hline No & 15 & 27 \\
\hline \multicolumn{3}{|l|}{ Complete relief of renal colic } \\
\hline Yes & 26 & 49 \\
\hline No & 20 & 6 \\
\hline \multicolumn{3}{|l|}{ Occurrence of SIRS } \\
\hline Yes & 9 & 2 \\
\hline No & 37 & 53 \\
\hline
\end{tabular}

No abortion or premature delivery occurred in any patient. Binary logistic regression analysis showed that history of childbirth, operation time, phloroglucinol application, relief of renal colic and SIRS occurrence were related to the presence of uterine contraction $(P<0.05)$. According to the statistical results, presence of SIRS after surgery (OR $0.099,95 \%$ CI $0.014-0.713$ ) was the risk factor for uterine contraction, meanwhile, no history of childbirth (OR 6.593, 95\% CI 2.231-19.490), shorter operation time(each quarter additional) (OR 2.385, 95\% CI 1.342-4.238), phloroglucinol application (OR 6.959, 95\% CI 1.416-34.194), complete relief of renal colic(OR 6.707, 95\% CI 1.978-22.738) were protective factors for uterine contraction (Table 3).

\section{Discussion}

At present, the definition of preterm birth is still controversial. Flenady et al. [17]. Pointed out that any childbirth within gestational age between 20 and 36 weeks could be defined as Preterm birth which was the main contributor of perinatal morbidity and the second leading cause of neonatal death in the world. The most common clinical symptom of urolithiasis during pregnancy was renal colic and mainly was observed after 20 weeks of gestation [18]. In consideration of ritodrine hydrochloride's instructions (only for pregnant women after 20 gestational week) and the difficulty for monitoring uterine contractions at early gestation [19], thereby we only retrospective analyzed pregnant women at 20 to 36 gestational week. Johnson et al. [12] had shown that the obstetric complications after ureteroscopy were about $4.0 \%$, but in our study there was nothing severe complication except for that $45.54 \%$ of patients developed to continuously regular contractions after ureteroscopy. The incidence of uterine contraction in our study was higher than that reported by other scholars [20]. The possible explanation were as follows: (1) all cases summarized in the study

Table 3 Risk factors for uterine contraction in pregnant women after ureteroscopy

\begin{tabular}{llll}
\hline Risk factors & OR & $95 \%$ CI & $P$ \\
\hline $\begin{array}{l}\text { History of deliveries } \\
\quad \text { Primipara versus multipara }\end{array}$ & 6.593 & $2.231-19.490$ & 0.001 \\
$\begin{array}{l}\text { Duration of surgery } \\
\quad \text { Short versus long }\end{array}$ & 2.385 & $1.342-4.238$ & 0.003 \\
$\begin{array}{l}\text { Application of phloroglucinol } \\
\quad \text { Yes versus no }\end{array}$ & 6.959 & $1.416-34.194$ & 0.017 \\
$\begin{array}{l}\text { Pain relief } \\
\quad \text { Complete versus incomplete }\end{array}$ & 6.707 & $1.978-22.738$ & 0.002 \\
$\begin{array}{l}\text { SIRS } \\
\text { Occurred versus not occurred }\end{array}$ & 0.099 & $0.014-0.713$ & 0.022 \\
\hline
\end{tabular}


were patients with severe renal colic which could not be relieved by painkiller in outpatient department, in view of the relevance between pain and uterine contraction, the incidence of such complication rose accordingly. (2) all patients were received uterine contraction monitoring by EHG for $12 \mathrm{~h}$ after surgery, thus any slight contractions which might be ignored by doctors could be detected in time and analyzed in our study, but in fact, some uterine contractions in early stage could disappear without any medical treatment. There was not any severe complications such as abortion or premature delivery occurred in this study, the results suggested that ureteroscopy was a relatively safe and effective surgical method. The results also reminded us that routine monitoring of uterine contractions after ureteroscopy might help to avoid pregnancy complications.

Compared with primipara, the cervix of multipara is easier to expand, which means a sooner labor process [21, 22]. Literature has shown that uterine contraction was stronger for multipara during labor and more analgesics were needed for painless delivery [23]. Our study showed that multipara were more likely to develop to uterine contraction after ureteroscopy. The possible explanations for this results were as follows: (1) compared with primipara, the oxytocin receptor which played a key role in uterine contraction had a higher expression on uterus in multipara [24, 25]; (2) with the increasing of age, the incidence of pregnancy complications rose in step, multipara was more likely to develop to uterine contraction after operation [26, 27].

Enlarged uterus due to pregnancy inevitably result in ureter compression because of the adjacent location between lower segment ureter and cervix [28-30]. The operation of ureteroscope would inevitably stimulate the cervix, long time and repeatedly physical stimulation could trigger uterine contraction. Scholars had shown that pregnancy complications were prone to occur after long-time surgery [31], and shortening operation time could reduce such complications [32]. Our results also indicated that long operation time was a risk factor for uterine contraction. This study showed that each additional a quarter increased, the adjusted odds ratio was as high as 2.385 . This result also reminded us that surgeons should shorten operation time as much as possible when ureteroscopy were performed on pregnant women. The purpose of ureteroscopy was just to resolve urethral obstruction, not for stone free.

Phloroglucinol, as a non-papaverine antispasmodic, only acts on spastic smooth muscles and has minimal impact on normal smooth muscles. Application of phloroglucinol during pregnancy does not increase the risk of fetal malformations [33]. It was applied to relieve renal colic and inhibit uterine contractions for decades [34, 35]. Our research showed that application of phloroglucinol after ureteroscopy could reduce the incidence of uterine contractions. In this study, only a few doctors prescribed phloroglucinol to patients after ureteroscopy, but the results indicated again that such drug may inhibit uterine contraction caused by renal colic for pregnant women.

If severe pain persists, human body would release prostaglandins which could promote cervical ripening and lead to smooth muscle contraction in uterine [36, 37]. Pain could also cause stress response and then trigger an increasing release of catecholamines that plays an important role in uterine contractions [38]. Furthermore, severe renal colic often accompanies with repeated vomit which may lead to uterus compression. Mechanical stimulation could also induces uterus contractions [39]. Our research also showed that unrelieved pain after surgery was a risk factor for uterine contractions. Twenty six patients in this study had little relief in renal colic immediately after ureteroscopy. The result was coincide with other reports [3]. The possible explanations was that the double $\mathrm{J}$ catheter inserted into ureter during operation did not play a effective role in drainage soon after surgery. With painkiller prescribed, pain in these patients gradually subsided in $12 \mathrm{~h}$ after operation.

During the operation of ureteroscopy, continuously intraureteral perfusion by saline is required. Increasing water pressure in ureter would force bacteria flow back into blood via renal pelvic-vein system, it is more likely to happen in patients with urinary tract infection. Bacteremia may result in spread of inflammation or even progress to SIRS which could develop to multiple organ dysfunction syndrome (MODS) [40]. Inflammatory mediators would be release and spread if SIRS occurs, such mediators could lead to uterus contraction [41, 42]. Our research also suggested that SIRS was a risk factor for uterus contraction. Pregnant women were more likely to develop to sepsis due to immunosuppression and down regulation of inflammatory response because of immunotolerance in pregnancy [43]. pregnant women with SIRS or sepsis may easily be ignored because of unconspicuous fever and quick heart rate caused by ritodrine hydrochloride [44], therefore, it is necessary to closely monitor the infection indicators, such as white blood cells, CRP, and PCT-Q and so on, in order to find potential infection in time and prevent uterus contraction caused by inflammation.

\section{Limitations}

There are also some limitations in this study. First, this study is a single center retrospective study, and the number of patients collected is not adequate enough; Second, there are many factors that may play a role in uterine contraction, such as scar uterus, but it is difficult to collect enough clinical feature by retrospective analysis; Thirdly, in this study, all patients only received uterine contraction monitoring for $12 \mathrm{~h}$ by EHG after surgery, but some contractions would not occur within $12 \mathrm{~h}$ and would be ignored. 


\section{Conclusion}

Ureteroscopy is considered to be a safe and effective treatment for pregnant women, but the high incidence of uterine contraction after surgery still calls for more attention. In order to reduce the odds of uterine contraction after operation, surgeon are supposed to finish the operation as soon as possible, prescribe phloroglucinol after operation, relieve pain and control infection effectively, and pay more attention to multipara.

Acknowledgements We would like to thank the staff at Foshan Maternal and Child Health care Hospital for clinical and administrative assistance and patients for contributing in this study.

Author contributions GL and SZ designed the study. ML monitored medication application, MG and JL collected and analyzed data. $\mathrm{CL}$ and LG wrote the paper. All authors have read and approved the manuscript.

Funding This project was made possible in part through the support of Guangdong Medical Science and Technology Research Fund Project (A2021240), Guangdong Medical Science and Technology Research Fund (20205792148508), Natural Science Foudation Committe of Fujian (2020J0112), Foshan maternal and child healthcare hospital research fund (FEYJZX-2020-002).

Data availability The data used and analyzed in this study are available from the corresponding author on reasonable request. The data that support the findings of this study has been upload as attachment in submission

\section{Declarations}

Conflict of interest The authors declare that they have no competing interests.

Ethical approval The study received approval on May 26, 2020 by Ethics Committee of Foshan Maternal and Child Healthcare Hospital (protocol number FSFY-MEC-2020-022).

Consent to participate Written informed consent for participation was obtained.

Open Access This article is licensed under a Creative Commons Attribution 4.0 International License, which permits use, sharing, adaptation, distribution and reproduction in any medium or format, as long as you give appropriate credit to the original author(s) and the source, provide a link to the Creative Commons licence, and indicate if changes were made. The images or other third party material in this article are included in the article's Creative Commons licence, unless indicated otherwise in a credit line to the material. If material is not included in the article's Creative Commons licence and your intended use is not permitted by statutory regulation or exceeds the permitted use, you will need to obtain permission directly from the copyright holder. To view a copy of this licence, visit http://creativecommons.org/licenses/by/4.0/.

\section{References}

1. Masselli G, Weston M, Spencer J (2015) The role of imaging in the diagnosis and management of renal stone disease in pregnancy. Clin Radiol 70(12):1462-1471. https://doi.org/10.1016/j. crad.2015.09.002 (Epub 2015 Oct 9 PMID: 26454345)

2. Pedro RN, Das K, Buchholz N (2016) Urolithiasis in pregnancy. Int J Surg 36(Pt D):688-692. https://doi.org/10.1016/j.ijsu. 2016.10.046 (Epub 2016 Nov 2 PMID: 27816709)

3. Fontaine-Poitrineau C, Branchereau J, Rigaud J, Bouchot O, Caroit-Cambazard Y, Glémain P (2014) Coliques néphrétiques de la femme enceinte: étude d'une série de cent trois cas [Renal colic in pregnancy: series of 103 cases]. Prog Urol 24(5):294 300. https://doi.org/10.1016/j.purol.2013.09.021 (Epub 2013 Oct 25. PMID: 24674335)

4. Sallami S, Ben Rhouma S, Ben Rais N, Horchani A (2011) La colique néphrétique chez la femme enceinte ou allaitante: problèmes diagnostiques et thérapeutiques [Renal colic in pregnancy and lactation: diagnostic and therapeutic approaches]. Tunis Med 89(7):593-597 (PMID: 21780032)

5. Bjazevic J, Razvi H (2018) Stones in pregnancy and pediatrics. Asian J Urol. 5(4):223-234. https://doi.org/10.1016/j.ajur. 2018.05.006 (Epub 2018 Jun 5. PMID: 30364569; PMCID: PMC619756)

6. Blanco LT, Socarras MR, Montero RF, Diez EL, Calvo AO, Gregorio SAY, Cansino JR, Galan JA, Rivas JG (2017) Renal colic during pregnancy: diagnostic and therapeutic aspects. Literature review. Cent Eur J Urol. 70(1):93-100. https://doi.org/10.5173/ ceju. 2017.754 (Epub 2016 Oct 28. PMID: 28461996; PMCID: PMC5407324)

7. Semins MJ, Matlaga BR (2013) Kidney stones and pregnancy. Adv Chronic Kidney Dis 20(3):260-264. https://doi.org/10. 1053/j.ackd.2013.01.009 (PMID: 23928391)

8. Rosenberg E, Sergienko R, Abu-Ghanem S, Wiznitzer A, Romanowsky I, Neulander EZ, Sheiner E (2011) Nephrolithiasis during pregnancy: characteristics, complications, and pregnancy outcome. World J Urol 29(6):743-747. https://doi.org/10.1007/ s00345-011-0719-7 (Epub 2011 Jun 21 PMID: 21691721)

9. Andreoiu M, MacMahon R (2009) Renal colic in pregnancy: lithiasis or physiological hydronephrosis? Urology 74(4):757-761. https://doi.org/10.1016/j.urology.2009.03.054 (Epub 2009 Aug 5 PMID: 19660792)

10. Committee on Practice Bulletins-Obstetrics, American College of Obstetricians and Gynecologists (2004) Dystocia and augmentation of labor. Int J Gynaecol Obstet 85(3):315-324. https://doi. org/10.1016/s0020-7292(04)00096-7 (PMID: 15216860)

11. Namavar Jahromi B, Salarian L, Shiravani Z (2011) Maternal risk factors and neonatal outcome of the admitted patients for preterm spontaneous uterine contractions. Iran Red Crescent Med J 13(12):877-883 (Epub 2011 Dec 1. PMID: 22737433; PMCID: PMC3371908)

12. Johnson EB, Pais VM Jr (2012) Obstetric complications of ureteroscopy during pregnancy. J Urol. https://doi.org/10.1016/j.juro. 2012.09.052 (Epub ahead of print. PMID: 22986037)

13. Chopra A, Radhakrishnan R, Sharma M (2020) Porphyromonas gingivalis and adverse pregnancy outcomes: a review on its intricate pathogenic mechanisms. Crit Rev Microbiol 46(2):213-236. https://doi.org/10.1080/1040841X.2020.1747392 (Epub 2020 Apr 8 PMID: 32267781)

14. Songthamwat $\mathrm{S}, \mathrm{Na}$ Nan $\mathrm{C}$, Songthamwat M (2018) Effectiveness of nifedipine in threatened preterm labor: a randomized trial. Int J Womens Health 15(10):317-323. https://doi.org/10.2147/IJWH. S159062.PMID:29942162;PMCID:PMC6007202 
15. ACOG Committee on Practice Bulletins-Obstetrics (2007) ACOG Practice Bulletin No. 80: premature rupture of membranes. Clinical management guidelines for obstetrician-gynecologists. Obstet Gynecol. https://doi.org/10.1097/01.AOG.0000263888.69178.1f (PMID: 17400872)

16. Zhang Y, Luo H, Wang H, Zheng Z, Ooi OC (2020) Validation of prognostic accuracy of the SOFA score, SIRS criteria, and qSOFA score for in-hospital mortality among cardiac-, thoracic-, and vascular-surgery patients admitted to a cardiothoracic intensive care unit. J Card Surg 35(1):118-127. https://doi.org/10.1111/ jocs.14331 (Epub 2019 Nov 11 PMID: 31710762)

17. Flenady V, Reinebrant HE, Liley HG, Tambimuttu EG, Papatsonis DN (2014) Oxytocin receptor antagonists for inhibiting preterm labour. Cochrane Database Syst Rev. https://doi.org/10.1002/ 14651858.CD004452.pub3 (PMID: 24903678)

18. Abdel-Kader MS, Tamam AA, Elderwy AA, Gad M, El-Gamal MA, Kurkar A, Safwat AS (2013) Management of symptomatic ureteral calculi during pregnancy: experience of 23 cases. Urol Ann 5(4):241-244. https://doi.org/10.4103/0974-7796.120294. PMID:24311902;PMCID:PMC3835980

19. Kantas E, Cetin A, Kaya T, Cetin M (2002) Effect of magnesium sulfate, isradipine, and ritodrine on contractions of myometrium: pregnant human and rat. Acta Obstet Gynecol Scand 81(9):825-830. https://doi.org/10.1034/j.1600-0412.2002. 810904.x (PMID: 12225296)

20. Hoşcan MB, Ekinci M, Tunçkıran A, Oksay T, Özorak A, Özkardeş H (2012) Management of symptomatic ureteral calculi complicating pregnancy. Urology 80(5):1011-1014. https://doi. org/10.1016/j.urology.2012.04.039 (Epub 2012 Jun 13 PMID: 22698475)

21. Zhang L, Troendle J, Branch DW, Hoffman M, Yu J, Zhou L, Duan T, Zhang J (2018) The expected labor progression after labor augmentation with oxytocin: a retrospective cohort study. PLoS ONE 13(10):e0205735. https://doi.org/10.1371/journal. pone.0205735.PMID:30379856;PMCID:PMC6209192

22. Albrecht K, Lam G (2008) Preterm spontaneous uterine rupture in a non-labouring grand multipara: a case report. J Obstet Gynaecol Can 30(7):586-589. https://doi.org/10.1016/S17012163(16)32892-4 (PMID: 18644180)

23. Duan G, Yang G, Peng J, Duan Z, Li J, Tang X, Li H (2019) Comparison of postoperative pain between patients who underwent primary and repeated cesarean section: a prospective cohort study. BMC Anesthesiol 19(1):189. https://doi.org/10. 1186/s12871-019-0865-9.PMID:31640565;PMCID:PMC68 06491

24. Genís S, Arís A, Kaur M, Cerri RLA (2018) Effect of metritis on endometrium tissue transcriptome during puerperium in Holstein lactating cows. Theriogenology 122:116-123. https://doi. org/10.1016/j.theriogenology.2018.09.004 (Epub 2018 Sep 15 PMID: 30245334)

25. Budden A, Chen LJ, Henry A (2014) High-dose versus lowdose oxytocin infusion regimens for induction of labour at term. Cochrane Database Syst Rev. https://doi.org/10.1002/14651858. CD009701.pub2 (PMID: 25300173)

26. Du Q, Jovanović S, Tulić L, Sljivančanin D, Jack DW, Zižić V, Abdul KS, Tulić I, Jovanović A (2013) KATP channels are up-regulated with increasing age in human myometrium. Mech Ageing Dev 134(3-4):98-102. https://doi.org/10.1016/j.mad. 2013.01.003 (Epub 2013 Jan 28 PMID: 23369859)

27. Berger R, Rath W, Abele H, Garnier Y, Kuon RJ, Maul H (2019) Reducing the risk of preterm birth by ambulatory risk factor management. Dtsch Arztebl Int 116(50):858-864. https://doi. org/10.3238/arztebl.2019.0858.PMID:31931955;PMCID: PMC6970314

28. Vigueras Smith A, Cabrera R, Zomer MT, Ribeiro R, Talledo R, Kondo W (2020) Laparoscopic transabdominal cerclage for cervical incompetence: a feasible and effective treatment in 10 steps. J Minim Invasive Gynecol 27(5):1025-1026. https://doi. org/10.1016/j.jmig.2019.10.019 (Epub 2019 Oct 31 PMID: 31678560)

29. Grosjean J, Cannie M, de Meyer JM (2017) L'hydronéphrose physiologique durant la grossesse: prévalences et causes possibles. Une étude basée sur l'IRM [Physiological hydronephrosis in pregnancy: occurrence and possible causes. An MRI study]. Prog Urol 27(12):603-608. https://doi.org/10.1016/j.purol. 2017.07.241 (Epub 2017 Aug 30 PMID: 28869171)

30. McLaren R, Bayya V, Irani M (2018) A 34-week size uterus with a complete hydatidiform mole: hook effect and severe anemia with no vaginal bleeding. Case Rep Obstet Gynecol. https:// doi.org/10.1155/2018/8201949 (PMID: 29670785; PMCID: PMC5833876)

31. Jenkins TM, Mackey SF, Benzoni EM, Tolosa JE, Sciscione AC (2003) Non-obstetric surgery during gestation: risk factors for lower birthweight. Aust N Z J Obstet Gynaecol 43(1):27-31. https://doi.org/10.1046/j.0004-8666.2003.00001.x (PMID: 12755343)

32. Guterman S, Mandelbrot L, Keita H, Bretagnol F, Calabrese D, Msika S (2017) Laparoscopy in the second and third trimesters of pregnancy for abdominal surgical emergencies. J Gynecol Obstet Hum Reprod 46(5):417-422. https://doi.org/10.1016/j. jogoh.2017.03.008 (Epub 2017 Mar 31 PMID: 28934085)

33. Lacroix I, Hurault-Delarue C, Kessler S, Guitard C, Vidal S, Albouy-Cossard C, Montastruc JL, Damase-Michel C (2011) Premières données épidémiologiques sur le phloroglucinol et exposition au cours du premier trimestre de grossesse [First epidemiologic data about phloroglucinol exposure during first trimester of pregnancy]. Gynecol Obstet Fertil 39(12):694-697. https://doi.org/10.1016/j.gyobfe.2011.07.013 (Epub 2011 Aug 19. PMID: 21855385)

34. Blanchard C, Pouchain D, Vanderkam P, Perault-Pochat MC, Boussageon R, Vaillant-Roussel H (2018) Efficacy of phloroglucinol for treatment of abdominal pain: a systematic review of literature and meta-analysis of randomised controlled trials versus placebo. Eur J Clin Pharmacol 74(5):541-548. https://doi. org/10.1007/s00228-018-2416-6 (Epub 2018 Jan 19 PMID: 29350249)

35. Yuan S, Gao F, Xin Z, Guo H, Shi S, Shi L, Yang X, Guan J (2019) Comparison of the efficacy and safety of phloroglucinol and magnesium sulfate in the treatment of threatened abortion: a meta-analysis of randomized controlled trials. Medicine (Baltimore) 98(24):e16026. https://doi.org/10.1097/MD.0000000000 016026.PMID:31192955;PMCID:PMC6587576

36. Herington JL, O'Brien C, Robuck MF, Lei W, Brown N, Slaughter JC, Paria BC, Mahadevan-Jansen A, Reese J (2018) Prostaglandin-endoperoxide synthase 1 mediates the timing of parturition in mice despite unhindered uterine contractility. Endocrinology 159(1):490-505. https://doi.org/10.1210/en. 2017-00647.PMID:29029054;PMCID:PMC5761592

37. Mohan AR, Loudon JA, Bennett PR (2004) Molecular and biochemical mechanisms of preterm labour. Semin Fetal Neonatal Med 9(6):437-444. https://doi.org/10.1016/j.siny.2004.08.001 (PMID: 15691781)

38. van der HoutJagt MB, Jongen GJ, Bovendeerd PH, Oei SG (2013) Insight into variable fetal heart rate decelerations from a mathematical model. Early Hum Dev. https://doi.org/10. 1016/j.earlhumdev.2012.12.001 (Epub 2012 Dec 27. PMID: 23273866)

39. Andreatta P, Gans-Larty F, Debpuur D, Ofosu A, Perosky J (2011) Evaluation of simulation-based training on the ability of birth attendants to correctly perform bimanual compression as obstetric first aid. Int J Nurs Stud 48(10):1275-1280. https://doi. 
org/10.1016/j.ijnurstu.2011.03.001 (Epub 2011 Mar 29 PMID: 21450290)

40. Zhong W, Leto G, Wang L, Zeng G (2015) Systemic inflammatory response syndrome after flexible ureteroscopic lithotripsy: a study of risk factors. J Endourol 29(1):25-28. https://doi.org/ 10.1089/end.2014.0409 (PMID: 24999535)

41. Lappas M (2012) Visfatin regulates the terminal processes of human labour and delivery via activation of the nuclear factor- $\kappa \mathrm{B}$ pathway. Mol Cell Endocrinol 348(1):128-134. https://doi.org/10.1016/j.mce.2011.07.048 (Epub 2011 Aug 4 PMID: 21839801)

42. Kobayashi H (2012) The entry of fetal and amniotic fluid components into the uterine vessel circulation leads to sterile inflammatory processes during parturition. Front Immunol 23(3):321. https://doi.org/10.3389/fimmu.2012.00321.PMID: 23109934;PMCID:PMC3478564
43. Robinson DP, Klein SL (2012) Pregnancy and pregnancy-associated hormones alter immune responses and disease pathogenesis. Horm Behav 62(3):263-271. https://doi.org/10.1016/j. yhbeh.2012.02.023 (Epub 2012 Mar 3. PMID: 22406114; PMCID: PMC3376705)

44. Bauer ME, Lorenz RP, Bauer ST, Rao K, Anderson FWJ (2015) Maternal deaths due to sepsis in the state of michigan, 1999-2006. Obstet Gynecol 126(4):747-752. https://doi.org/10.1097/AOG. 0000000000001028.PMID:26348189;PMCID:PMC4564866

Publisher's Note Springer Nature remains neutral with regard to jurisdictional claims in published maps and institutional affiliations. 